\title{
FARABI
}

Jurnal Pemikiran Konstruktif Bidang Filsafat dan Dakwah

ISSN $1907-0993$

E ISSN $2442-8264$

Vol. 16 No. 1, Juni 2019

\section{MASTURAH; KERJA DAKWAH ISTRI JAMAAH TABLIGH}

\author{
Gina Nurvina Darise ${ }^{1 *}$ \\ Sunandar $\mathrm{Macpal}^{2}$ \\ ${ }^{1}$ IAIN Manado, ginadarise@yahoo.co.id \\ 2. IAIN Sultan Amai Gorontalo, Indonesia, sunandarmacpal@gmail.com
}

\begin{abstract}
Tablighi Jamaat is the name given by the community to a group of people who carry out da'wah / tabligh from mosque to mosque. Because this congregation is performing at all times, the term "Tablighi Jamaat or JT" appears. Apart from husbands, the wives of the tabligh congregation are obliged to maintain the da'wah business at home and always support the da'wah work carried out by their husbands, because basically masturah (women) efforts can have a strong influence to give birth to generations of warriors of Allah's religion and future preachers, so that clearly that masturah (woman) business is an important part of da'wah work. This study intends to explain how the da'wah is carried out by the wife of Tablighi Jamaat. The findings of this research are that the da'wah of a woman / wife of a tabligh (masturah) can be carried out in two ways, namely: amal maqami women at home such as, enlivening the atmosphere of knowledge, enlivening the atmosphere of the mosque, enlivening the sunnah, enlivening tarbiyah walad, enlivening the atmosphere of da'wah and enlivening service and the second one goes in the way of Allah i.e. three days every 3-4 months, fifteen days, forty days and two months India and Pakistan.
\end{abstract}

Keywords: Da'wah, Tablighi Jamaat, Masturoh

Abstrak: Jamaah tabligh adalah nama yang diberikan oleh masyarakat kepada sekelompok orang yang melakukan dakwah/tabligh dari masjid ke masjid. Karena jamaah ini setiap saat bertabligh, maka munculah istilah "jamaah tabligh atau JT". Selain suami, istri jamaah tabligh berkewajiban menjaga usaha dakwah di rumah dan senantiasa mendukung kerja dakwah yang dilakukan oleh suaminya, karena pada dasarnya usaha masturah (wanita) dapat memberikan pengaruh yang kuat untuk melahirkan generasi pejuang agama Allah dan para dai masa depan, sehingga dengan jelas bahwa usaha masturah (wanita) adalah bagian penting dalam kerja dakwah. Penelitian ini bermaksud menjelaskan bagaimana dakwah yang dilakukan oleh istri dari Jamaah Tablig. Temuan dari penelitian ini adalah dakwah seorang wanita/istri jamaah tabligh (masturah) dapat dilaksanakan dengan dua cara yakni: amal maqami wanita di rumah seperti, menghidupkan suasana ilmu, menghidupkan suasana masjid, menghidupkan suasana sunnah, menghidupkan tarbiyah walad, menghidupkan suasana dakwah dan menghidupkan perkhidmatan dan yang kedua pergi di jalan Allah yakni tiga hari setiap $3-4$ bulan sekali, lima belas hari, empat puluh hari dan dua bulan India dan Pakistan.

Kata kunci: Dakwah, Jamaah Tablig, Masturoh 


\section{FARABI}

Jurnal Pemikiran Konstruktif Bidang Filsafat dan Dakwah

ISSN $1907-0993$

E ISSN $2442-8264$

Vol. 16 No. 1, Juni 2019

\section{A. PENDAHULUAN}

Islam adalah agama yang universal, yang mengatur seluruh tatanan kehidupan sosial keagamaan masyarakat baik yang menyangkut hal kehidupan duniawi maupun kehidupan akhirat, salah satunya adalah mengenai gerakan dakwah. Islam sebagai agama disebut agama dakwah, maksudnya adalah agama yang disebarluaskan dengan cara damai tidak lewat kekerasan. Walaupun ada terjadi peperangan dalam sejarah Islam, baik itu di zaman Nabi Muhammad SAW masih hidup atau di zaman sahabat dan sesudahnya, peperangan itu bukanlah dalam rangka menyebarkan atau mendakwahkan Islam, tetapi dalam rangka mempertahankan diri umat Islam atau melepaskan masyarakat dari penindasan yang tirani. ${ }^{1}$

Sulit memisahkan dakwah dengan Islam karena Islam sendiri berkembang lewat dakwah. Sesuatu yang tidak dapat dipungkiri bahwa dakwah sebagai kegiatan menyampaikan ajaran Islam sama tuanya dengan Islam itu sendiri. Hal tersebut dapat dibuktikan dengan turunnya perintah kepada Nabi Muhammad saw untuk menyampaikan apa yang datang dari Allah swt kepada keluarga terdekat sesuai dengan firman Allah swt Q.S al-Syu'ra (26:214).

Secara umum, kata dakwah berasal dari unsur bermakna mengajak, meminta, memanggil atau menyeru. Dalam Al-Qur'an, menurut Muh. Fuad Abdul Baqi perintah dakwah terulang sebanyak 213 kali. $^{2}$ Ditinjau dari segi bahasa, dakwah berarti panggilan, ajakan, seruan. Dakwah dengan pengertian seperti di atas dapat dijumpai dalam ayat Al-Qur'an antara lain Q.S Yusuf ayat 33. Dakwah merupakan kewajiban bagi setiap laki-laki muslim dan wanita muslim seperti tersirat dalam Q.S. Al-Maidah: 67, An-Nahl: 44 dan 125, Al Ahzab: 45-46 dan Al-Jumu'ah: 2.

Untuk hal di atas, kita semua kaum muslimin, baik laki-laki maupun perempuan perlu memperhatikan tugas atau kerja yang dapat meningkatkan iman dan

\footnotetext{
${ }^{1}$ Moh Ali Aziz, Ilmu Dakwah (Jakarta; Kencana,2004), h. 1

${ }^{2}$ Hamiruddin, Gerakan Dakwah Al-Nadzir, (Cet. I; Makassar: Alauddin University Press, 2014), h. 94.
} 


\section{FARABI}

Jurnal Pemikiran Konstruktif Bidang Filsafat dan Dakwah

ISSN $1907-0993$

E ISSN $2442-8264$

Vol. 16 No. 1, Juni 2019

amal sholeh di lingkungan kaum muslimin dan keluarganya. Jumlah wanita ini lebih banyak dari jumlah laki-laki dan jumlah anak-anak lebih banyak daripada jumlah wanita saat ini. Jika saat ini kita tidak buat usaha agama atas kaum wanita dan anakanak, maka kita akan kehilangan sebagian besar dari umat ini. Maka penting dari kaum wanita harus mempunyai kesadaran akan tanggungjawab agama dan usaha atas agama. $^{3}$

Dikalangan masyarakat Islam banyak metode dakwah yang dilakukan oleh para Da'i, salah satunya adalah dakwah yang dilakukan oleh kalangan yang bernama Jamaah tabligh (JT). Hal yang sangat menarik dari metode dakwah yang dilakukan oleh Jamaah tabligh (JT) ialah apabila sedang melakukan dakwah atau biasa disebut dengan tabligh mereka mempunyai metode yang biasa mereka sebut dengan khuruj fii sabilillah. Khuruj adalah meluangkan waktu untuk secara total berdakwah yang biasanya dari masjid ke masjid dan dipimpin oleh seorang Amir. ${ }^{4}$ Ketika dalam masa berdakwah meninggalkan istri dan anak kewajiban sebagai seorang suami terhadap istri dan anak harus tetap dipenuhi karena setiap anggota keluarga telah memiliki hak dan kewajibannya masing-masing, begitupun sebaliknya seorang istri jamaah tabligh berkewajiban menjaga usaha dakwah di rumah dan senantiasa mendukung kerja dakwah yang dilakukan oleh suaminya, karena pada dasarnya usaha masturah (wanita) dapat memberikan pengaruh yang kuat untuk melahirkan generasi pejuang agama Allah dan para dai masa depan, sehingga dengan jelas bahwa usaha masturah (wanita) adalah bagian penting dalam kerja dakwah.

Tulisan ini kemudian mencoba mengkaji lebih lanjut bagaimana metode kerja dakwah yang dilakukan oleh perempuan dalam Jamaah Tabligh. Penelitian ini menggunakan metode studi pustaka yang bersumber dari buku-buku, jurnal-jurnal dan hasil penelitian yang berhubungan dengan kerja dakwah bagi perempuan dalam

\footnotetext{
${ }^{3}$ Buya Athaillah, Nasehat Dakwah: Kumpulan Bayan Masturat (Jakarta, CV. Athaillah, tth), h. 24 .

${ }^{4}$ Khusniati Rofiah, Dakwah Jamaah tabligh \& Eksistenisnya di mata masyarakat (Ponorogo: Ponorogo Press, 2010), h,78.
} 


\section{FARABI}

Jurnal Pemikiran Konstruktif Bidang Filsafat dan Dakwah

ISSN $1907-0993$

E ISSN $2442-8264$

Vol. 16 No. 1, Juni 2019

jamaah tabligh. Tulisan ini kemudian dibagi menjadi lima bagian, di mana bagian pertama merupakan pendahuluan; bagian kedua merupakan profil dari jamaah tabligh; bagian ketiga berisi hak dan kewajiban suami istri Jamaah Tabligh; bagian keempat menjelaskan kerja dakwah perempuan Jamaah Tabligh dan bagian kelima merupakan kesimpulan.

\section{B. PROFIL JAMAAH TABLIGH}

Jamaah tabligh adalah sebuah nama yang diberikan oleh masyarakat, bukan nama yang diberikan oleh Pendirinya Syekh Maulana Muhammad Iyas. Karena setiap hari berjamaah dan bertabligh maka muncullah istilah ini. Maulana Muhammad Ilyas dilahirkan pada tahun 1885. Ia menghabiskan masa kecilnya di kampung kakeknya dari pihak Ibu di Kandahla dan bersama ayahnya di Nizamuddin. Pada masa itu keluarga Kandahla merupakan tempat lahirnya sifat-sifat kewalian dan ketaqwaan. ${ }^{5}$

Maulana Ilyas sangat risau menyaksikan sebagian besar umat Islam kala itu tidak menjalankan syariat agamanya dalam kehidupannya sehari-hari. Sebagian masih berkutat dalam kebiasaan adat yang bertentangan dengan syariat, sebagian lagi malah mengikuti kebudayaan barat yang di bawa oleh penjajah.

Maka berbagai upaya diusahakan tetapi hasilnya kurang memuaskan hatinya. Ketika sedang I'tikaf di Masjid Nabawi di Madinah al-Munawarah, Maulana Ilyas mendapat inspirasi untuk menghidupkan kembali cara Rasulullah dan para sahabat menghidupkan suasana agama dan da'wah Ilallah ke seluruh penjuru dunia, yaitu dengan cara mengirimkan rombongan demi rombongan, membawa mereka dari suasana jahil dibawa ke tempat yang hidup suasana agama. Sekelompok demi sekelompok kecil orang awam dikirim ke tempat yang hidup suasana agamanya untuk belajar agama terutama mengenai iman dan amal shalih. Dengan cara demikian, mereka jelas tidak akan diganggu oleh kesibukan lain, bahkan akan menumpuk

${ }^{5}$ Syid Abu Hasan Ali an Nadwi, Sejarah Maulana Ilyas Mempelopori Jamaah tabligh Menggerakkan Khuruj fii sabilillah (Bandung:Pustaka Ramadhan,tth), h.7 


\section{FARABI}

Jurnal Pemikiran Konstruktif Bidang Filsafat dan Dakwah

ISSN $1907-0993$

E ISSN $2442-8264$

Vol. 16 No. 1, Juni 2019

perhatiannya kepada Al-Qur'an, mempelajari perintah-perintah syariat dan mendengarkan riwayat hidup para sahabat Rasulullah saw dengan demikian mereka akan kembali ke tempat asal mereka dengan keadaan yang lebih baik.

Mula-mula orang mewat yang kala itu hanya namanya saja yang muslim tapi kehidupannya sehari-hari jauh dari agama, akhlaknya pun merosot. Mereka dikrim ke Kandahla, yang merupakan tempat pendidikan Islam yang terkenal. Metode ini ternyata mencapai keberhasilan yang cukup berarti, dalam waktu yang tidak terlalu lama, di Mewat mulai hidup suasana agama.

Inilah asal mula khuruj fii sabilillah, yaitu berangkat dari suatu tempat ke tempat yang lain untuk memperdalam iman dan amal shalih. Dengan metode ini hingga sekarang telah dikirim jamaah demi jamaah ke seantero dunia untuk tujuan da'wah illallah. Kegiatan ini netral untuk semua faham dalam Islam dan menghindari pembicaraan-pembicaraan mengenai politik, khilafiyah, aib masyarakat atau status sosial, juga tidak meminta derma. Metode ini meniru jamaah tabligh yang dikirim oleh Rasulullah saw, yang terdiri dari para sahabat untuk menyebarkan dan menghidupkan Islam keseluruh dunia. Hal yang paling mendasar dari gerakan jamaah tabligh adalah mereka selalu mengajak kepada memakmurkan masjid dan menghidupkan amalan silaturahmi.

Metode dakwah yang dilakukan oleh Jamaah tabligh ini dengan cara khuruj fii sabilillah berlandaskan ketika mimpi pendiri Jamaah tabligh itu sendiri yaitu Syeikh Maulana Ilyas, beliau bermimpi mengenai tafsir Q.S Al-Imron ayat 110. Dalam ayat di atas terdapat kalimat ukhrijat yang kemudian ditafsirkan dengan makna keluar untuk mengadakan perjalanan, dan keluar itulah yang dimaksud dengan dakwah. ${ }^{6}$

Sebagaimana yang dikemukakan oleh Maulana Ilyas bahwa: setiap orang yang beriman hendaknya meluangkan waktu untuk mendakwahkan agama ke setiap rumah dengan membentuk rombongan khuruj. Menelurusi lorong demi lorong, rumah

\footnotetext{
${ }^{6}$ Khusniati Rofiah, op.cit, h.82
} 


\section{FARABI}

Jurnal Pemikiran Konstruktif Bidang Filsafat dan Dakwah

ISSN $1907-0993$

E ISSN $2442-8264$

Vol. 16 No. 1, Juni 2019

demi rumah, kota demi kota dengan bersabar menghadapai kesulitan dan mengajak manusia dengan baik untuk memperjuangkan agama. ${ }^{7}$

Khuruj sendiri adalah meluangkan waktu untuk secara total berdakwah yang biasanya dari masjid ke masjid dan dipimpin oleh seorang Amir. ${ }^{8}$ Dalam melakukan hal tersebut para anggota Jamaah tabligh (JT) keluar meninggalkan keluarganya untuk melakukan waktunya ke berbagai penjuru desa, kota bahkan mancanegara dalam jangka waktu tertentu antara 3-40 hari, 4-7 bulan bahkan satu tahun.

Fahim (2009) mengemukakan adanya sembilan (9) ciri khas dalam dakwah yang dilakukan oleh Jamaah Tablih yang menjadi pembeda dengan harokah lainnya yaitu: (1) mendatangi manusia dengan berjalan kaki/'alal aqdam; (2) degan menggunakan modal yakni harta dan diri (3) Dakwah mereka kepada akar bukan ranting yakni kepada Iman bukan Fiqh (4) tidak ikut suasana dan keadaan (5) dimulai dari keutamaan amal (6) Orang bodoh, orang miskin, orang pendosa menjadi sasaran dakwah (7) Tidak terkesan dengan kekuasaan (8) tidak terkesan dengan harta (9) tidak berpolitik (10) tidak meminta upah. ${ }^{9}$

Sewaktu khuruj, kegiatan diisi dengan ta'lim (membaca hadits atau kisah sahabat, biasanya dari kita Fadhail amal karya Maulana Zakaria), jaulah (mengunjungi rumah-rumah disekitar masjid tempat khuruj dengan tujuan mengajak kembali pada Islam yang kaffah), bayan, mudzkarah (menghafal) 6 sifat sahabat, karkuzari (memberi laporan harian pada amir), dan musyawarah. Selama khuruj mereka tidur di masjid.

Dalam dakwah jamaah tabligh selalu diajarkan Mudzakarah enam sifat (kebenaran mutlak yang berasal dri Allah swt, yaitu Al-Qur'an dalam enam sifat). Enam sifat tersebut yaitu:

\footnotetext{
${ }^{7}$ Maulana Muhammad Yusuf Al-Kandahlawi, Enam Sifat Para Sahabat Nabi dan Amalan Nurani (Bandung: Pustaka Ramadhan,2005), h. 3

${ }^{8}$ Khusniati Rofiah, op.cit, h,78.

9 Abu Muhammad Fahim, Kedok Jamaah tabligh (Jakarta; Yasa, 2009), h.34.
} 


\section{FARABI}

Jurnal Pemikiran Konstruktif Bidang Filsafat dan Dakwah

ISSN $1907-0993$

E ISSN $2442-8264$

Vol. 16 No. 1, Juni 2019

1. Yakin ke pada kalimah thayyibah, Laa Illaha illah Allah Muhammad Rasulullah

Artinya: Tidak ada yang berhak disembah kecuali Allah swt

Maksudnya : mengeluarkan keyakinan kepada makhluk dari hati

kita dan memasukkan keyakinan hanya kepada Allah ke dalam hati

kita

2. Shalat khusyu wal khudhu

Artinya : Shalat yang diiringi konsentrasi batin dan merendahkan diri dihadapan Allah serta dilakukan dengan cara Rasulullah

Maksudnya : membawa sifat-sifat ketaatan kepada Allah yang ada dalam shalat kedalam kehidupan sehari-hari

3. Ilmu ma'a dzikir

Artinya : segala petunjuk yang datang dari Allah swt. Melalui baginda Rasulullah swa, mengingat Allah sebagimana agungnya Allah swt.

Maksudnya : mengamalkan perintah-perintah Allah swt. Setiap saat dan setiap keadaan serta melakukannya dengan cara Rasulullah saw.

4. Ikramul muslimin

Artinya $\quad$ : memuliakan sesama saudara muslim

Maksudnya : menunaikan hak-hak saudara muslim tanpa menuntut hak-hak kita dari mereka

5. Tashhiihun Niyyah

Artinya : memperbaiki atau membutulkan niat

Maksudnya : membersihkan niat kita dalam setiap amal dari niatniat lain kecuali hanya untuk mencari keridhaan Allah swt.

6. Da'wah wa al-Tabligh

Artinya : Mengajak dan menyampaikan 


\section{FARABI}

Jurnal Pemikiran Konstruktif Bidang Filsafat dan Dakwah

ISSN $1907-0993$

E ISSN $2442-8264$

Vol. 16 No. 1, Juni 2019

Maksudnya : untuk memperbaiki diri agar kita dapat mempergunakan harta, diri dan waktu sesuai dengan perintah Allah. Untuk menghidupkan agama secara sempurna pada diri kita sendiri dan pada diri seluruh manusia di seluruh alam.

Hal yang paling mendasar dari gerakan Jamaah tabligh adalah mereka selalu mengajak kepada memakmurkan masjid dan menghidupkan amalan silaturahmi.

Sesungguhnya pergerakkan jamaah tabligh diseluruh dunia, memiliki aturan penyeleksian sebelum khuruj, aturan ini dikenal dikalangan jamaah tabligh dengan istilah 'tafaqud'. Tafaqud ini meliputi: amwal, amal dan ahwal. Amwal adalah yang berhubungan dengan masalah biaya yaitu biaya untuk selama perjalanan dan biaya untuk keluarga yang ditinggalkan. Semua itu disesuaian dengan lamanya ia keluar dan daerah yang akan dituju. Sedangkan Ahwal adalah yang berkaitan dengan masalah keluarga, pekerjaan dan sejenisnya.

Seseorang akan dibenarkan khuruj 40 hari atau 4 bulan atau beberapa pun lamanya, jika dia telah melewati proses tafaqud tadi. Sehingga tidak benar tuduhan yang mengatakan bahwa Jamaah tabligh meninggalkan keluarga begitu saja, tanpa meninggalkan perbekalan bagi keluarganya atau menyia-nyiakannya. Selanjutnya, walaupun sudah dipastikan seseorang itu lulus tafaqud untuk khuruj, maka kawankawan Jamaah tabligh yang tidak sedang khuruj, secara bergilir akan memperhatikan hal ihwal keluarga yang sedang ditinggalkannya tersebut. ${ }^{10}$

\section{HAK DAN KEWAJIBAN SUAMI-ISTRI JAMAAH TABLIGH}

\section{Hak Istri ${ }^{11}$}

a. Mengingatkan suami dalam hal ketaatan,

\footnotetext{
${ }^{10}$ Abdurrahman Ahmad, Kupas Tuntas Jamaah tabligh (Buku 1) (Cirebon:Pustaka Nabawi, 2010), h.66

${ }^{11}$ Ust Musthafa Sayani, Kemuliaan wanita shalilah (Bandung:Pustaka Ramadhan,2007), h. 91
} 


\section{FARABI}

Jurnal Pemikiran Konstruktif Bidang Filsafat dan Dakwah

ISSN $1907-0993$

E ISSN $2442-8264$

Vol. 16 No. 1, Juni 2019

b. Mendorong dan membantu suami dalam mengamalkan dan memperjuangkan agama.

\section{Kewajiban Istri ${ }^{12}$}

a. Istri harus taat kepada suaminya dalam semua aspek yang menyenangkannya walaupun harus meringkas amalan-amalan agama yang sunnat,

b. Istri harus menjaga auratnya dari sentuhan orang-orang asing (yang bukan mahram)

c. Seorang istri tidak boleh membelanjakan sesuatu yang mungkin tidak bernilai bagi suami

d. Istri tidak boleh meninggalkan rumah sebelum minta izin kepada suami ataupun tidak boleh mengunjungi rumah-rumah tetangga kalau suaminya tidak membolehkannya datau tidak boleh memasukkan orang-orang yang tidak disukai oleh suaminya kedalam rumahnya

e. Istri harus berusaha untuk mencari keridhaan suaminya, ini adalah rahasia kesuksesan kehidupan rumah tangga karena keridhaan Allah swt terletak pada keridhaan suami, barulah istri tersebut bisa mendapatkan surga

f. Mencintai suami dan menghargai teman-teman suami

g. Istri harus berterima kasih kepada suamianya. Suami adalah dermawan kepada istrinya

h. Istri harus merasa gembira melayani suami walaupun mengorbankan kesenangan sendiri

i. Istri harus memperhatikan rumah suaminya dan orang-orang yang ada dalam rumahnya

j. Istri harus memelihara kebersihan dan kerapihan rumah.

\section{Hak Suami ${ }^{13}$}

12 Alimudiin Tuwu, Bimbingan Nikah Dan Membina Rumah Tangga Menurut Al-Quran Sunah Terj. Kitaabun Nikah (Bandung:Pustaka Ramadhan,2008), h.104 


\section{FARABI}

Jurnal Pemikiran Konstruktif Bidang Filsafat dan Dakwah

ISSN $1907-0993$

E ISSN $2442-8264$

Vol. 16 No. 1, Juni 2019

a. Istri menjaga ketaatan pada suami

b. Istri menjaga harta kehormatan dirinya

c. Istri menjaga harta suaminya

d. Istri menjaga lisan terhadap suami (tidak menyakiti suami dengan perkataannya)

\section{Kewajiban Suami ${ }^{14}$}

a. Suami harus memperlakukan istrinya dengan baik

b. Suami tidak boleh menghina isterinya dengan segala kekurangan pada dirinya, karena tidak ada lelaki dan wanita yang tidak mempunyai kekurangan

c. Suami tidak boleh memukul istrinya

d. Suami harus menyiapkan waktu senggang untuk bersenang-senang secara khusus dengan istri

e. Suami harus memberi makan, pakaian, dan tempat perlindungan kepada istrinya

f. Suami harus memberikan pendidikan dasar tentang Islam, kesehatan dan ilmu kesehatan kepada istrinya

g. Suami harus membayar maharnya apabila diminta, sebaliknya apabila suami tidak membayar mahar sedang sitrinya meminta maka sitri dapat menolak berhubungan dengan suami sebagai hak dari suatu pernikahan

h. Suami sebagai pelindung terhadap istrinya dari hal-hal yang tidak bermoral dan sebagai penghibur dalam keadaan-keadaan yang sulit

Hikmah yang didapat seseorang ketika melakukan khuruj fii sabilillah bagi istri dan anaknya ketika selesai berdakwah atau pulang ke rumah adalah

a. Khidmat kepada keluarga, masyarakat dan menjadi bunga kepada keluarga.

Ketika pulang ke rumah setelah berdakwah seorang suami bahkan dapat
${ }^{13}$ Ibid
${ }^{14}$ Ibid, h. 100. 


\section{FARABI}

Jurnal Pemikiran Konstruktif Bidang Filsafat dan Dakwah

ISSN $1907-0993$

E ISSN $2442-8264$

Vol. 16 No. 1, Juni 2019

melakukan hal-hal yang membuat istri bahagia diantaranya adalah suami dapat memasak, karena ketika khuruj fii sabilillah sudah terbiasa dengan hal tersebut,

b. Zikir ibadah didalam rumah bersama anggota keluarga

c. Talim di rumah (memasukkan ajaran agama ke dalam rumah)

d. Dakwah dengan cara lemah lembut

e. Menjadikan rumah seperti rumahnya Nabi saw. Hidup sederhana seperti: hidup menurut kadar keperluan, seperti dalam makan, minum, pakaian dan kendaraan. ${ }^{15}$

Khidmat terhadap suami bagi para istri Jamaah tabligh dan dapat pula dikatakan sebagai kewajiban istri terhadap suami diatur seperti senantiasa menunaikan hak suami, setia kepada suami, berhias hanya untuk suami (bukan untuk orang lain), menaati perintahnya, menyenangkan suami, tidak bermuka masam kepada suami, menjaga harta suami, bersabar atas keburukkan suami, melayani keperluan suami dengan sebaik mungkin, tidak menuntut duniawi secara berlebihan, menghargai kebaikan suami, dan senantiasa berwarna cerah. ${ }^{16}$ Lalu, seorang wanita atau istri dikalangan jamaah tabligh memiliki 3 tanggungjawab, yaitu pertama ketaatan kepada Allah swt, kedua menghidupkan agama pada diri sendiri, ketiga mentarbiyah anak secara Islam dan mendorong laki-laki keluar di jalan Allah ${ }^{17}$

Ketika dalam masa berdakwah meninggalkan istri dan anak kewajiban sebagai seorang suami terhadap istri dan anak harus tetap dipenuhi karena setiap anggota keluarga telah memiliki hak dan kewajibannya masing-masing. Setiap keluarga yang ingin ditinggal khuruj fii sabilillah oleh suami diadakan musyawarah terlebih dahulu. Seluruh anggota keluarga diberitahu seperti istri dan anak-anak bahwa mereka akan ditinggal selama beberapa lama (3 hari, 40 hari dan 4 bulan), setelah diadakan musyawarah dan istri maupun anggota keluarga lainnya setuju maka suami dan istri

\footnotetext{
15 Muhammad Qosim, Panduan keluar pada jalan Allah (khuruj fii sabilillah) (Bandung: Pustaka Ramadhan,2009), h.66

${ }^{16}$ Abdurrahman Ahmad, Mudzakarah Masturat (Cirebon: Pustaka Nabawi,2009), h.56

${ }^{17}$ Abu Abidah, Bayan Mastrah seri 2 (Jakarta: Annisa Photoshop, 2008), h.46
} 


\section{FARABI}

Jurnal Pemikiran Konstruktif Bidang Filsafat dan Dakwah

ISSN 1907 - 0993

E ISSN 2442 - 8264

Vol. 16 No. 1, Juni 2019

menghitung besaran nafkah yang akan ditinggalkan oleh suami dalam kurun waktu ia berdakwah. Contoh, dalam satu hari keluaraga salah satu anggota jamaah tabligh mereka menghabiskan uang sebanyak Rp. 100.000 (Seratus ribu rupiah) untuk biaya makan dan kebutuhan anak-anak sekolah serta kebutuhan lainnya. Maka, seorang suami ketika ingin khuruj fii sabilillah dalam kurun waktu 3 hari meninggalkan uang Rp. 100.000 X 3 = Rp. 300.000 begitupula ketika ingin khuruj fii sabilillah dalam kurun waktu lainnya, yaitu 40 hari dan 4 bulan. Apabila ditinggal oleh suami selama 4 bulan (120 hari), maka Rp. 100.000, X 120 hari = Rp. 12.000.000,- ${ }^{18}$

Beberapa hal yang hendaknya ditanamkan oleh seorang wanita solehah terhadap nafkah yang diberikan suaminya adalah selalu bersyukur, berhemat, jangan menuntut lebih, menggunakannya dengan izin suami, puas dengan nafkah yang ada dan digunakan untuk kepentingan agama. ${ }^{19}$ Sebelum melakukan khuruj, dilakukan pembinaan keluarga, terutama ibu-ibu dan wanita diadakan ta'lim ibu-ibu yang namanya masturat, artinya tertutup atau terhijab. Dalam pembinaan itu, wanita atau ibu-ibu dilatih mandiri. Sehingga ketika ditinggal khuruj mereka sudah bisa berperan sebagai kepala rumah tangga di rumah.

\section{DAKWAH ISTRI JAMAAH TABLIGH}

Jumlah wanita ini lebih banyak dari jumlah laki-laki dan jumlah anak-anak lebih banyak daripada jumlah wanita saat ini. Jika saat ini kita tidak buat usaha agama atas kaum wanita dan anak-anak, maka kita akan kehilangan sebagian besar dari umat ini. Maka penting dari kaum wanita harus mempunyai kesadaran akan tanggungjawab agama. Dan usaha atas agama. ${ }^{20}$

Sehingga dengan jelas bahwa usaha masturah (wanita) adalah bagian penting dalam kerja dakwah. Seorang istri akan selalu menjaga usaha dakwah di rumah dan senantiasa mendukung kerja dakwah yang dilakukan oleh suaminya. Bahkan usaha

\footnotetext{
${ }^{18}$ Abu Targhibi, Targhib Masturah (Jakarta:Assalam,tth), h. 15.

19 Abdurrahman Ahmad,Fadhillah Wanita Shalilah (Cirebon:Pustaka Nabawi, tth), h.102

${ }^{20}$ Buya Athaillah, op.cit, h.24.
} 


\section{FARABI}

Jurnal Pemikiran Konstruktif Bidang Filsafat dan Dakwah

ISSN $1907-0993$

E ISSN $2442-8264$

Vol. 16 No. 1, Juni 2019

masturah dapat memberikan pengaruh yang kuat untuk melahirkan generasi pejuang agama Allah, para dai masa depan. Sehinnga seorang Bapak dapat mendorong kepada anaknya sebagai dai, seperi mana ucapan Lukman kepada anaknya ${ }^{21}$ seperti dalam Q.S Lukman ayat 17.

Jika kita tidak membuat usaha wanita ini bisa menjadi alat untuk tegaknya kebatilan, sebagaimana wanita juga bisa dapat menjadi sebab tegaknya yang haq. Wanita ini mempunyai perananan yang penting dalam kehidupan laki-laki. Ini dikarenakan: "satu kata wanita ini mampu menundukkan keinginan laki-laki". Satu pertakaan wanita yang buruk ebagaimana yang terjadi pada Nabi Adam AS diturunkan dari surga sebab bujukan ibu Hawa begitu juga dengan Nabi yusuf dipenjara sebab perkataan Zulaikha. Begitu juga denga satu kata kebaikan dari wanita sebagaimana yang terjadi pada Amr bin Jamuh RA, sahabat yang cacat menjadi syahid sebab targhib (diberikan semangat) oleh istrinya dan seorang firaun tunduk pada keinginan istrinya, Asiyah RA ketika menemukan bayi Musa AS dan ingin mengangkatnya sebagai anak. Inilah kekuatan dari wanita, apabila kekuatan ini digunakan untuk agama maka dampaknya akan besar bagi kehidupan manusia. Sebagaiman yang terjadi pada zaman Rasulullah SAW, di mana dua khalifah dari empat orang khalifah memeluk Islam karena peranan wanita: Umar bin Khattab RA: sebab taklim adik perempuannya; dan Utsman bin Affan RA: sebab dakwah bibinya, Arwa R.ha

Tingkat pengorbanan tertinggi di jalan Allah adalah ketika seseorang telah mengorbankan seluruh hartanya dan nyawa di jalan Allah. Jika kita berbicara pengorbanan:

1. Allah swt telah pilih Khadijah R.ha yang pertama berkorban dengan hartanya

2. Allah swt telah pilih Summayah R.ha sebagai syahidah pertama

Jika kita lihat dari sejarah Islam maka Nabi-nabi yang dibantu oleh istrinya dalam kerja dakwah mereka maju dan hidayah tersebar lebih banyak seperti nabi

\footnotetext{
${ }^{21}$ Ibid,h.26.
} 


\section{FARABI}

Jurnal Pemikiran Konstruktif Bidang Filsafat dan Dakwah

ISSN $1907-0993$

E ISSN $2442-8264$

Vol. 16 No. 1, Juni 2019

Ibrahim S, Musa AS, Muhammad swa. Namun nabi-nabi yang tidak didukung oleh istrinya maka dakwahnya tidak banyak membuahkan hasil seperti Nabi Nuh as dan Luth as. ${ }^{22}$

Disinilah peranan wanita dalam menentukan maju atau tidaknya suatu usaha. Khususnya dalam usaha agama. Apalagi di saat rusaknya keadaan umat hari ini, sangat penting bagi kita untuk buat usaha atas wanita. Kita sangat berhajat pada keterlibatan wanita dalam menegakkan agama. Tidak mungkin agama bisa berkembang hanya melalui peran laki-laki saja. Peran kaum wanita dalam memperjuangkan agama juga sangat diperlukan, mengingat jumlah perempuan dan anak-anak lebih banyak daripada laki-laki.

Memperbaiki diri ini adalah perintah Allah, berdakwah kepada keluarga juga perintah Allah. Namun agar keluarga bisa ikut dalam usaha perbaikan, maka perlu kita perbaiki diri kita terlebih dahulu. Allah swt perintahkan kita untuk memperbaiki diri kita agar bisa membimbing keluarga kita ke jalan Allah swt. ${ }^{23}$

Maka bagi kaum wanita dibutuhkan 2 usaha :

1. Amal maqami wanita,

2. Pergi di jalan Allah

Amal maqami wanita di rumah :

1. Hidupkan suasana ilmu :taklim rumah,

2. Hidupkan suasana masjid : zikir ibadat,

3. Hidupkan suasana sunnah :kesederhanaan,

4. Hidupkan tarbiyah walad :mudzakaroh dan dakwah illallah dengan anak

5. Hidupkan suasana dakwah : musyawarah harian dengan suami dan tasykil

6. Hidupkan perkhidmaan: suasana akhlaq.

Pergi di jalan Allah :

1. Tiga hari setiap $3-4$ bulan sekali

\footnotetext{
${ }^{22}$ Ibid., h.5

${ }^{23} \mathrm{Ibid}$, h. 38
} 


\section{FARABI}

Jurnal Pemikiran Konstruktif Bidang Filsafat dan Dakwah

ISSN $1907-0993$

E ISSN $2442-8264$

Vol. 16 No. 1, Juni 2019

2. Lima belas hari

3. Empat puluh hari

4. Dua bulan India dan Pakistan.

Target masturat (wanita/istri):

1. Menjadi daiyah,

Jumlah wanita lebih banyak dari laki-laki dan jumlah anak-anak lebih banyak dari wanita. Jika Allah mau mewujudkan agama di suatu kaum, maka Allah kirimkan Nabi-Nabi. Sudah menjadi ketentuan Allah swt semua Nabi adalah laki-laki. Namun seberapa besar hidayah tersebar, ini yang Allah lihat adalah pengorbanan istri-istri Nabi, bukan Nabinya

Maksud dari wanita menjadi Daiyah:

a. Mendorong suami untuk dakwah dan fii sabilillah,

b. Menyiapkan anak-anak menjadi dai-daiyah, alim-alimah, hafidz-hafidzah.

c. Untuk menanamkan fikir dan risau atas kaum wanita,

d. Menghidupkan dakwah di kalangan kaum wanita.

Cara mendapatkannya:

a. Hidupkan musyawarah rumah harian: fikir nusroh Jemaah, fikir tasykil keluarga, fikir agama

b. Apabila datang kawan-kawan wanita maka dakwahkan kepada mereka kebesaran Allah, pentingnya agama dan usaha atas agama.

c. Keluar 3 hari setiap 3 bulan, 15 hari, 40 hari dan 2 bulan IP (India,Pakistan). ${ }^{24}$

2. Menjadi alimah,

Syarat diterimanya amal ini adalah jika memahami, mengetahui, dan mengamalkan hukum-hukum agama seperti :syarat sahnya wudhu, shalat, mandi wajib, halal dan haramnya makanan, sampai dengan adab berjima. Bagaimana amalan seorang istri bisa diterima jika dia tidak mengetahui

\footnotetext{
${ }^{24}$ Ibid,h. 40-41
} 


\section{FARABI}

Jurnal Pemikiran Konstruktif Bidang Filsafat dan Dakwah

ISSN $1907-0993$

E ISSN $2442-8264$

Vol. 16 No. 1, Juni 2019

syarat-syarat sahnya suatu amal dan apa yang membatalkan amal tersebut. Apalagi ibu ini adalah tempat bertaya bagi para anak-anaknya.

Cara mendapatkannya :

a. Buat taklim rumah + mudzakaroh,

b. Hadir dalam taklim mingguan,

c. Meminta suami agar bertanya kepada ulama mengenai masalah Fiqh wanita.

3. Menjadi abidah,

Melibatkan istri untuk membawa suasana masjid kedalam rumah kita. Amalamal sholeh yang kita hidupkan di rumah ini akan mendatangkan suasana malaikat yang hadir dalam rumah kita. Jika ada amal maka malaikat akan berkemurun. Jika malaikat hadiri maka yang datang adalah suasana sakinah, mawaddah, warahmah. Namun, jika tidak hidup suasana agama di rumah kita maka yan akan datang suasana setan dan suasan maksiat ke dalam rumah kita, sehinnga akan mebuat rumah kita menjadi angker dan panas. Jika suasana yang Haq ditegakkan di rumah kita, maka suasan yang bathil akan sirna sebagimana kegelapan akan hilang oleh cahaya.

Maksud dan tujuan menjadikan istri ini sebagai abidah adalah:

Agar para istri kita mampu dan mau menghidupkan amalan dzikir ibadah di rumah kita dapat hidup suasana amal bukan suasana maksiat. ${ }^{25}$

Cara mendapatkannya :

a. Menghidupkan shalat wajib di awal waktu di rumah,

b. Menghidupkan shalat-shalat sunnat dari dhuha, awwabin, qobla, ba'diah, tahajjud, tasbih dll

c. Menghidupkan bacaan Quran minimal 1 juz setiap hari

d. Menghidupkan dzikir pagi petang dan wirid harian

e. Menjaga doa-doa masnunah.

${ }^{25} \mathrm{Ibid}$, h. 43 


\section{FARABI}

Jurnal Pemikiran Konstruktif Bidang Filsafat dan Dakwah

ISSN $1907-0993$

E ISSN $2442-8264$

Vol. 16 No. 1, Juni 2019

4. Menjadi murobbiyah,

Al Umm Madrasatul Kubro artinya Ibu itu adalah sekolah/pendidik terbaik bagi anak-anaknya. Ibu ini adalah pendidik generasi yang darinya akan lahir dan tercetak anak-anak yang akan mencintai Allah dan RasulNya ataupun menjadi musuh-musuh Allah dan RasulNya.

Maksud dan tujuan menjadi Murobbiyah ini adalah :

Agar lahir dari Rahim wanita-wanita sholihah ini generasi-generasi yang mencintai agama dan amalan agama. ${ }^{26}$

Cara mendapatkannya:

a. Menghidupkan dakwah illallah kepada anak (membentuk yakin),

b. Menghidupkan taklim dan mudzakaroh (mengenalkan agama)

c. Libatkan dalam amal ibadah (cinta pada amal agam)

d. Libatkan dalam perkhidmatan (membentuk akhlaq)

e. Menjaga adab-adab : makn, minum, berpakaian tidur, taklim kepada orang tua

5. Menjadi zahidah,

Zahidah atau ahli zuhud ada;ah orang-orang yang rela mengorbankan harta ataupun kesukaannya demi agama ataupun akheratnya dengan hidup sederhana. Ciri-ciri orang yang zuhud adalah kesederhanaan. Kesederhanaan adalah ciri kehidupan Nabi saw dan keluarganya. Sedangkan kehidupan yang paling Allah cintai adalah kehidupan Nabi saw dan keluarganya. Jika kebutuhan dan keperluan kita ini bisa disederhanakan, dizuhudkan, maka takaza akherat akan dapat terpenuhi. Kenapa takaza agama hari ini sulit terpenuhi karena kehidupan kita ini penuh dengan sifat boros dan mubazir.

Cara mendapatkannya dengan menunaikan hak harta tersebut :

a. Sisihkan untuk dakwah (maksud hidup)

b. Sisihkan untuk ibadah (hablum minnallah)

\footnotetext{
${ }^{26}$ Ibid, h. 44
} 


\section{FARABI}

Jurnal Pemikiran Konstruktif Bidang Filsafat dan Dakwah

ISSN $1907-0993$

E ISSN $2442-8264$

Vol. 16 No. 1, Juni 2019

c. Sisihkan untuk sedekah dam Infaq (membentuk akhlaq:hablum minannas)

d. Keperluan sederhana (sunnah utama rumah tangga Nabi saw)

Apabila itu keperluan yang sederhana :

a. Makan minum sederhana,

b. Pakaian sederhana,

c. Rumah dan isinya sederhana,

d. Kendaraan sederhana,

e. Walimah sederhana

6. Menjadi khadimah.

Akhlaq yang baik ini akan terbentuk melalui perkhidmatan. Mujahadah wanita yang paling utama adalah melayani ataukhidmat kepada suami, inilah sebabnya ridho Allah ada bersama ridho suami. ${ }^{27}$

Maksud dan tujuan menjadi khadimah adalah agar perkhidmatan yang dilakukan istri bisa mendorong suami untuk pergi di jalan Allah.

Cara mendapatkannya adalah :

a. Jika dipandang suami menyenangkan

b. Jika berbicara kepada sumi tidak menyakiti

c. Jika diperintah suami dia taat

d. Jika ditinggalkan suami dia bisa menjaga harta suami dan kehormatannya $^{28}$

Usaha masturah merupakan usaha untuk memberikan kepahaman kepada kaum ibu atau perempuan bahwa mereka pun mempunyai tugas untuk saling membantu dalam usaha dakwah. Mereka juga harus membangun keluarganya di masa depan.

Ta'lim harian dirumah merupakan program yang sangat penting bagi keluarga muslim. Saat ini program ini sangat berkurangan, dan sangat sedikit kaum muslimin mengadakan ta'lim harian. Ta'lim harian yang perlu sering dilakukan adalah ta'lim

${ }^{27}$ Ibid, h. 48

${ }^{28}$ Ibid, h, 49 


\section{FARABI}

Jurnal Pemikiran Konstruktif Bidang Filsafat dan Dakwah

ISSN $1907-0993$

E ISSN $2442-8264$

Vol. 16 No. 1, Juni 2019

fadhilah amal. Ta'lim ini akan memberikan dorongan kepada anggota keluarga untuk selalu menjaga amal-amal sholeh, seperti shalat zikir, puasa, dakwah, silaturahmi, akhlaq, menuntut ilmu, mengikuti para sahabat, ikram kepada kaum muslim dll. Sedangkan untuk ta'lim masail (tentang cara beramal) dapat mengikutinya dari para ustadz atau ustadzah yang kita percaya.

Baca qur'an harian merupakan sesuatu yang baik dan ini perlu dilakukan bersama keuarga. Bahkan beberapa daerah yang sudah sangat berkembang dengan usaha dakwah, sudah banyak anggota keluarga uang mulai menekankan untuk banyak hafidzh Qur'an di rumahnya, sehingga biasanya orang tua yang sudah memahami usaha dakwah ini mendorong keluarganya sendiri untuk banyak hafalan quran dan juga hafalan hadis.

Biasanya diadakan bayan masturah agar kaum ibu banyak yang memahami usaha dakwah ini dan mendorong suaminya dan juga anggota keluarga lainnya untuk dapat terlibat dalam usaha dakwah ini. Dalam taklim masturah diadakan juga halaqah tajwid untuk mendorong kaum ibu agar lebih bersemangat dalam mempelajari Alquran. Pada program bayan masturah ini, tidak hanya diikuti oleh keluarga ahli dakwah, tetapi juga dapat diiukuti kaum ibu tetangga rumah dimana ada bayan masturah atau kaum muslimah lainnya dan yang terpenting dapat diperhatikan adabadabnya dengan baik.

Disamping hal tersebut, kadangkala dikeluarkan rombongan khusus masturah, artinya dikirimkan rombongan dakwah bersama istri-istri ahli dakwah. Aktifitas rombongan ini sama dengn rombongan yang tanpa istri, hanya saja ada programprogram khusus masturah ketika di tempat ang dituju, seperti bayan masturah, program ta'lim wa ta'allum khusus muslimah di daerah itu, program halaqah qur'an dan lain-lain. ${ }^{29}$

\footnotetext{
${ }^{29} \mathrm{Ibid}$, h. 22-23.
} 


\section{FARABI}

Jurnal Pemikiran Konstruktif Bidang Filsafat dan Dakwah

ISSN $1907-0993$

E ISSN $2442-8264$

Vol. 16 No. 1, Juni 2019

\section{E. PENUTUP}

Dakwah bagi kelompok Jamaah Tabligh bukan hanya untuk kalangan lakilaki saja, melainkan juga perempuan. Dakwah seorang wanita/istri jamaah tabligh (masturah) dapat dilaksanakan dengan dua cara yakni: amal maqami wanita di rumah seperti, menghidupkan suasana ilmu, menghidupkan suasana masjid, menghidupkan suasana sunnah, menghidupkan tarbiyah walad, menghidupkan suasana dakwah dan menghidupkan perkhidmatan dan yang kedua pergi di jalan Allah yakni tiga hari setiap $3-4$ bulan sekali, lima belas hari, empat puluh hari dan dua bulan India dan Pakistan.

\section{DAFTAR PUSTAKA}

Abidah, Abu, Bayan Masturah seri 2, Jakarta:Annisa Photoshop, 2008

Ahmad, Abdurrahman, Kupas Tuntas Jamaah Tabligh (Buku 1), Cirebon:Pustaka Nabawi, 2010

-, Mudzakarah Masturat, Cirebon:Pustaka Nabawi,2009

,Fadhillah Wanita Shalilah, Cirebon:Pustaka Nabawi, tth

Ali an Nadwai, Syid Abu Hasan, Sejarah Maulana Ilyas Mempelopori Jamaah tabligh Menggerakkan Khuruj fii sabilillah, Bandung:Pustaka Ramadhan,tth

Al-Kandahlawi, Maulana Muhammad Yusuf, Enam Sifat Para Sahabat Nabi dan Amalan Nurani Cet.I;Bandung:Pustaka Ramadhan,2005

Athaillah, Buya Athaillah, Nasehat Dakwah:Kumpulan Bayan Masturat, Jakarta,Cv. Athaillah, tth

Aziz, Moh Ali, Ilmu Dakwah, Jakarta;Kencana,2004

Fahim, Abu Muhammad Fahim, Kedok Jamaah Tabligh, Jakarta;Yasa, 2009 


\section{FARABI}

Jurnal Pemikiran Konstruktif Bidang Filsafat dan Dakwah

ISSN $1907-0993$

E ISSN $2442-8264$

Vol. 16 No. 1, Juni 2019

Hamiruddin, Gerakan Dakwah Al-Nadzir, Cet. I; Makassar: Alauddin University Press, 2014

Qosim Muhammad, Panduan keluar pada jalan Allah (khuruj fii sabilillah) Bandung:Pustaka Ramadhan,2009

Rofiah, Khusniati Rofiah, Dakwah Jamaah tabligh \& Eksistenisnya di mata masyarakat, Ponorogo:Ponorogo Press, 2010

Sayani, Musthafa Sayani, Kemuliaan wanita shalilah, Bandung:Pustaka Ramadhan,2007

Targhibi, Abu, Targhib Masturah, Jakarta:Assalam,tth

Tuwu, Alimudiin, Bimbingan Nikah Dan Membina Rumah Tangga Menurut AlQuran Sunah Terj. Kitaabun Nikah, Bandung:Pustaka Ramadhan,2008 